\title{
O uso do genograma como recurso expressivo e objeto mediador em grupo de crianças e adolescentes
}

\section{The use of the genogram as an expressive resource and object mediator in group of children and adolescents}

\author{
Michelle Joanny Zompero Santos ${ }^{1}$, Isabel Cristina Gomes ${ }^{2}$
}

\section{Resumo}

A prática do genograma familiar demonstra ser uma fonte significativa de investigação sobre as dinâmicas familiares, para além do manifesto, principalmente quando empregado como objeto mediador dentro do espaço de uma sessão terapêutica. Auxilia na descrição das relações familiares, estruturas vinculares, funções e papéis ocupados pelos membros de uma família ou grupo e facilita o acesso à figuração da transmissão psíquica inter e transgeracional. Com o objetivo de compreender como o genograma tem sido empregado em grupo de crianças e adolescentes, incluindo o de irmãos, realizou-se uma revisão narrativa da literatura nas principais bases de dados com as palavras chaves: genograma, grupo e crianças. Os resultados demonstraram que o genograma apresenta-se como um instrumento flexível, criativo, que se adapta a vários referenciais teóricos e contextos a serem utilizados.

Palavras-Chave: Genograma. Grupos. Crianças e adolescentes.

\begin{abstract}
The practice of the family genogram demonstrates a significant source of research on family dynamics, in addition to the manifest, especially when used as a mediator object within the space of a therapeutic session. It helps in the description of family relationships, structures with link, roles and roles occupied by the members of a family or group and facilitates access to the figuration of inter and transgenerational psychic transmission. With the purpose to understand how the genogram has been used in a group of children and adolescents, including siblings, a narrative review of the literature was carried out in the main databases with the key words: genogram, group and children. The results demonstrated that the genogram has been presented as a flexible, creative instrument, which adapts to various theoretical references and contexts to be used.
\end{abstract}

Keywords: Genogram. Groups. Children and adolescents.

\section{Introdução}

Considerado uma ferramenta e recurso expressivo gráfico, o genograma é uma espécie de árvore genealógica, uma representação visual do arquivo de histórias da família, utilizado por profissionais da área da saúde e da psicologia. Inicialmente usado por geneticistas, também foi muito aplicado no registro e acompanhamento por médicos das famílias. Posteriormente, foi associado

\footnotetext{
Psicóloga, mestranda em Psicologia Clínica pela Universidade de São Paulo (USP). Especialista em Psicoterapia de Orientação Analítica para crianças e adolescentes. E-mail: mzompero@usp.br

2 Livre-docente e professora titular do Departamento de Psicologia Clínica do IPUSP. Coordenadora do laboratório de Casal e família: Clínica e estudos psicossociais.
} 
à teoria de Bowen - o qual usa a própria família como um laboratório para testar suas ideias e conhece um caminho através do "sistema emocional familiar", denominado por ele de "impenetrável floresta" (MACEDO, 2014, p. 6). Inspirado na teoria boweniana, McGoldrick publica em $1985 \mathrm{seu}$ modelo teórico e de construção do genograma. O instrumento dedica-se à compreensão do sistema familiar e seu funcionamento, abrangendo os aspectos relacionais, emocionais e transgeracionais. Dessa forma, amplia, e muito, "as possibilidades de trabalhar com famílias, ajudando-as a perceber as interligações entre seus componentes, os padrões que se repetem, os cortes emocionais, as triangulações, enfim, o nível de diferenciação nas sucessivas gerações e suas influências." (MACEDO, 2014, p. 10).

Diferentemente do modelo racional apresentado anteriormente por Bowen, Wachtel (1982, p. 335) descreve o genograma como um método estruturado capaz de levantar a história familiar de pelo menos três gerações. Além disso, apresenta uma abordagem capaz de deixar transparecer sentimentos e de denunciar medos, desejos e valores não ditos e não pensados pelos indivíduos que compõem a unidade familiar, o que aproxima o uso do genograma a uma técnica denominada por ele "quase projetiva". A variedade de maneiras pelas quais o clínico pode usar o genograma, além do uso padrão descrito na literatura da época, é colocada em discussão, exemplificando com quem e sob quais circunstâncias o mesmo poderia ser empregado. $\mathrm{O}$ instrumento adquire, então, status semelhante aos testes psicológicos, o que agrega peso e credibilidade às suposições que um clínico pode fazer sobre as pautas familiares por meio de seu uso. (MGGOLDRICK; GERSON, 2000, p. 141; WACHTEL, 1982).

Com o passar do tempo, o genograma ganha maior rigor e transforma-se num instrumento sistemático e até científico. Recursos de software como, por exemplo, o GenoPro® são desenvolvidos para auxiliar na construção, na uniformização, no armazenamento e na apresentação de dados para as investigações qualitativas em trabalhos e estudos de família (COSTA, 2013).

$\mathrm{Na}$ contemporaneidade, é visto como um instrumento que permite o entendimento da estrutura e do funcionamento familiar por meio do conhecimento da história da família obtendo dados médicos, sociais, culturais, traços individuais de comportamento e personalidade, e também dos vínculos e relações emocionais de cada grupo. Como recurso para entrevistas, em pesquisas e psicodiagnósticos, tal ferramenta permite adquirir rapidamente uma grande quantidade de informações. $\mathrm{E}$, à medida que se obtêm detalhes sobre o histórico familiar, propicia uma visão dos problemas potenciais e uma melhor compreensão da demanda em questão. Acredita-se que, com o recurso do genograma, é possível ultrapassar questões da família nuclear e identificar determinados padrões familiares transmitidos e repetidos de geração em geração. (FRANCO; SEI, 2015; MCGOLDRICK; GERSON, 2000).

\section{O Genograma na Perspectiva Sistêmica}

Segundo a abordagem sistêmica de atendimento familiar, Zuse, Rossato e Backes (2002) apontaram que as famílias se repetem em si mesmas e, desta forma, o desenho do genograma ajuda a perceber, por meio de uma descrição gráfica do posicionamento dos membros da família, como estes estão biológica e legalmente ligados entre si. Assim também pode rastrear ansiedades e emoções através das gerações, do contexto familiar atual e dos pontos nodais de transição do ciclo vital, uma vez que permite visualizar a representação das pessoas e das suas relações. Nessa trajetória, vamos encontrando as tensões às mudanças e transições, o impacto dos fatos traumáticos, as dores ainda conservadas vivas com as perdas e mortes não resolvidas. Assim, aos poucos, o sistema vai se reportando às várias experiências críticas que acontecem aproximadamente sob a mesma época, criando um 
legado emocional que pressagia novas tragédias ou acontecimentos, como por exemplo, suicídios, acidentes, colapso mental, abuso de álcool, reações a aniversários, traumas transgeracionais que afetam o desenvolvimento emocional e cognitivo ou até mesmo o sucesso social, político ou econômico de um indivíduo que impacta fortemente a estrutura familiar. Aparentemente, algumas coincidências nos fazem pensar no abalo sobre o posterior desenvolvimento do indivíduo e tais questões poderiam nos ajudar a entender a disfunção do presente a serviço de um legado ou mito familiar. (MCGOLDRICK; GERSON, 2000, p. 103).

Para os autores citados, os indicadores que aparecem na construção do genograma são nossa "bússola" na terapia de família, pois a retomada da história da família e de determinadas intercorrências facilitam o processo de reorientações no tratamento. Da mesma maneira, é possível manter uma cronologia ou linha de tempo familiar junto à feitura do genograma, no intuito de ajudar no entendimento temporal e listar, em ordem de aparição, acontecimentos importantes na história da família que podem afetar o indivíduo. Pode-se, por exemplo, delimitar um período crítico de tempo com o objetivo de "rastrear" a enfermidade de um membro da família e sequenciar o sintoma com acontecimentos significativos. Ou ainda, realizar uma cronologia individual no intuito de investigar o curso de vida de um membro particular dentro do contexto familiar. (CERVENY, 2014, p. 20; MCGOLDRICK; GERSON, 2000, p. 33).

Além disso, Zuse, Rossato e Backes (2002, p. 315) acreditam que:

[...] o uso desse instrumento não se constitui apenas no mapa gráfico da estrutura familiar, como da sua evolução ao longo das gerações, mas, curiosamente, até na previsão de futuros eventos de forma que se possa realizar um trabalho de prevenção a longo prazo, com mudanças atuais.

$\mathrm{Na}$ prática, o uso do genograma como uma ferramenta clínica mostra-se bastante eficiente quando facilita ao terapeuta, que desconhece o caso, obter de maneira ágil, por meio do trabalho em conjunto, uma vasta quantidade de informações sobre a família e sobre o acontecimento traumático. No entanto, os genogramas são necessariamente esquemáticos e, apesar de utilizarem linhas distintas para simbolizar e compreender os tipos de relações entre os membros da família, podem se apresentar confusos e não detectarem todas as vicissitudes da história familiar. Logo, esta ferramenta demonstra limitações frente à diversidade das novas configurações contemporâneas de família e na difícil tarefa de traçar complexas redes de relações, em especial em casos de adoção ou de crianças que são criadas em casas distintas - como nos casos de guarda compartilhada. Nestas situações, concentrase muitas vezes apenas nas relações mais recentes que, geralmente, acabam sendo representadas por mais de um genograma. (MCGOLDRICK; GERSON, 2000).

São famílias monoparentais, recasadas, homoafetivas, filhos por adoção ou fertilização, indivíduos sem laços consanguíneos ocupando espaços importantes dentro da família e, às vezes, papéis desempenhados por pessoas diferentes daquelas que rotineiramente se espera. Como por exemplo, tios ou irmãos em funções paternas e maternas. Não raros são os estudos que mencionam a vulnerabilidade de tornar-se um "substituto" quando, por exemplo, a criança nasce próxima ao período de diagnóstico de enfermidade ou morte de um irmão recebendo, inclusive, o mesmo nome. Outra situação bastante comum refere-se ao fato de o irmão mais velho assumir a responsabilidade por dar continuidade às tradições familiares e, desse modo, tornar-se portador das grandes expectativas dos pais e de toda família, o que remete ao mito de Atlas, aquele que é designado a sustentar o gigantesco peso que fora condenado a "carregar nas costas".

Cada um tem seu lugar, tem seu papel dentro do grupo familiar; e toda vez que ocorre uma mudança, um fenômeno sistêmico acontece. Em vista disso, 
sem dúvida, como demonstrou Bowen no estudo sobre a posição de irmãos, ter conhecimento da constelação sistêmica da fratria pode fornecer, do ponto de vista clínico, explicações normalizadoras úteis sobre os papéis do sujeito em suas famílias, bem como indicar outros fatores para se investigar quando as configurações típicas não são encontradas. Deste modo, a diferença de idade entre irmãos, a posição fraterna de nascimento, atitudes e inclinações parentais sobre as diferenças de gênero, as características da criança (especial, enferma) e a posição fraterna da criança com respeito aos pais, dentre outros, podem se ver refletidas nos estilos de suas personalidades e podem, inclusive, predizer algumas dificuldades conjugais (MCGOLDRICK; GERSON, 2000; ZUSE; ROSSATO; BACKES, 2002).

Na terapia de casal e família, contudo, o uso da técnica - inicialmente sistêmica - se complementa com o enfoque psicanalítico. Nas colocações iniciais de Watchel (1982), todos que se utilizavam da técnica do genograma compartilhavam do interesse comum na história das dificuldades da família apresentada, no estudo da transmissão de padrões prévios armazenados, transformados e manifestados no presente e nas influências multigeracionais. Deste modo, espera-se ao utilizar o genograma que, por meio do reconhecimento dos pactos familiares e da transmissão psíquica, seja possível alertar e ajudar as famílias a não permanecer na repetição e evitar em gerações futuras (MCGOLDRICK; GERSON, 2000).

\section{A Perspectiva Psicanalítica}

Antes de prosseguir acerca do uso do genograma dentro do enfoque psicanalítico, considerou-se ser pertinente clarificar brevemente alguns conceitos na perspectiva da psicanálise vincular.

Kaës (2005) refere-se à transmissão psíquica como uma mensagem inconsciente não transformada que continua a ser transmitida de geração em geração e que faz de alguns descendentes depositários de um destino considerado “implacável”. Essa transmissão, denominada de transgeracional, "caracteriza-se pelas fixações psíquicas que são os segredos e os silenciamentos na história de uma família, a qual não consegue historiar seu passado e repete seu drama, sem transformá-lo" (KAËS, 2005, p. 132); podendo se efetuar pelas "alianças inconscientes" baseadas, por exemplo, no pacto denegativo,o qual Kaës classifica como:

[...] uma formação psíquica intersubjetiva construída pelos sujeitos de um vínculo para reforçar, em cada um deles, certos processos, certas funções ou certas estruturas advindas do recalque, ou da recusa, ou do desmentido e da qual eles obtêm benefícios, tal que, o vínculo que os liga adquire, para sua vida psíquica, um valor decisivo. As alianças inconscientes enodamse para que os sujeitos de um vínculo estejam assegurados de nada saber sobre seus próprios desejos, nem daqueles que os precederam. $\mathrm{O}$ conjunto assim ligado, só obtém sua realidade psíquica a partir das alianças, dos contratos e dos pactos inconscientes que esses sujeitos concluem e que, seu lugar no conjunto, obriga-os a manter. (KAËS, 2005, p. 133).

Em outras palavras, Kaës (2005, p. 129) explica que a transmissão se dá quando a falta, a ruptura ou o vazio não podem ser interpretados-significados e são "transportados, projetados, depositados e difratados" em um outro por meio dos vínculos intersubjetivos. Assim, cabe às nossas diversas memórias a complexa tarefa de "ressignificar, a partir do presente, a colocação em perspectiva do passado" a partir "da interrogação do sofrimento e de um destino de repetição". Reconstitui-se, assim, uma "versão possível" do passado silenciado construindo um espaço para poder pensar, refletir e simbolizar e, através da sua elaboração, tornar transmissível a história construída. (KAËS, 2005, p. 177-178).

A ambiguidade entre o poder falar, simbolizar e o desejo de calar estabelece uma ruptura, uma 
clivagem em forma de segredo que é transmitida de uma geração a outra. René Kaës acredita que aquilo que não pode ser dito ou falado, os "pactos denegativos" que são estabelecidos entre as gerações para evitar a dor e lembranças humilhantes, têm uma dimensão tão violenta quanto a própria situação traumática vivida em si (CORREA, 2000).

Desse modo, o pacto denegativo (fundado sobre o recalque neurótico) é o efeito de uma aliança inconsciente a qual diz respeito à descrição de "como e segundo que processos as alianças internas e as alianças nas relações se entrelaçam de tal modo que alguns de seus conteúdos, seus objetos, algumas de suas metas e entradas tornam-se e permanecem inconscientes aos sujeitos vinculados nessa aliança". (KAËS, 2014, p. 16). Porém, "aquilo que se transmite nas alianças e por elas, através de alguém e até através de mais de um alguém, através dos grupos e das formações sociais, é uma dimensão fundamental no quadro metapsíquico da vida psíquica do sujeito singular". (KAËS, 2014, p. 17).

Assim sendo, o pacto denegativo garante a função metadefensiva de cada sujeito na intenção de resolução de conflitos intrapsíquicos e conflitos que perpassam uma configuração de relações - quando se formam/estabelecem, ou ainda, na sua manutenção. (KÄ̈S, 2014, p. 112). Desta maneira, "para alguns aspectos ele faz parte das alianças necessárias à estruturação da relação, e para outros aspectos, ele funciona como uma das alianças alienantes". Mas, em ambos os casos, "seus efeitos se manifestam nas repetições e nos sintomas compartilhados, nos objetos bizarros ou enigmáticos, nos actings out". (KAËS, 2014, p. 118).

É importante destacar que o pacto, bem como qualquer aliança, não se estabelece apenas a partir do espaço interno, mas sim a partir de um espaço comum e compartilhado, o qual atribui "a cada um o seu lugar e a sua função de guardião ou de avalista do pacto". (KAËS, 2014, p. 119).
De acordo com Benghozi e Galery (2010, p. 24), "cada um é agente e desempenha um papel que lhes foi delegado por difração de lealdades genealógicas". Por conseguinte, os mitos familiares são um "conjunto de crenças compartilhadas pelos membros do grupo familiar" o qual atua como um organizador grupal familiar e define os contornos que caracterizam o "grupo de pertencimento". (BENGHOZI; GALERY, 2010, p. 24-25). Nesse sentido, a importância dos rituais familiares é assegurar a transmissão do mito fundador do grupo de pertencimento, por meio dos rituais de inclusão e exclusão do continente genealógico grupal familiar e ratificar uma transicionalidade do tempo genealógico. Da mesma forma, todos os mitos familiares "nos informam sobre as necessidades atuais e circulam para resolver contradições insolúveis". (BENGHOZI; GALERY, 2010, p. 25; BERENSTEIN, 2010, p. 68).

Pensando sobre isso, Benghozi e Galery (2010, p. 22) afirma que "a fratria é o grupo herdeiro da transmissão psíquica por difração das lealdades genealógicas". Segundo ele, "cada irmão e irmã é portador em níveis intra, inter e transpsíquicos”, encontrando-se aí a origem do vínculo fraterno com seus respectivos pactos, alianças e colusão (BENGHOZI; GALERY, 2010, p. 22). Sendo “o conjunto dessa herança singular, diferente em cada irmão e irmã, encontrada na fratria", que reconstitui o "todo" do patrimônio psíquico genealógico. Ou seja, Benghozi e Galery (2010, p. 23) considera "as características da herança psíquica, tão diversamente manifesta em cada irmão e irmã, como a singularidade de uma pluralidade grupal familiar. Cada sujeito se situa numa identificação dialética entre sujeito singular e sujeito de pertencimento". E diz que "a transmissão está para o vínculo, assim como a comunicação está para a relação" (BENGHOZI; GALERY, 2010, p. 23). Encontrase nesse ponto o pensar sobre a diferenciação entre as terapias de família ditas psicanalíticas e as ditas sistêmicas. 


\section{O Genograma Psicanalítico}

Aqui se retoma o instrumento genograma, com a abordagem de seu uso no campo da psicanálise e do atendimento psicoterápico, no qual é visto como atividade auxiliar que pode ser utilizada com uma maior liberdade e adaptação de acordo com o contexto. Na clínica de família, o genograma é bastante utilizado como instrumento de avaliação ao lado do Arte Diagnóstico Familiar (ADF) de Kwiatkowska (1975) e da Entrevista Familiar Estruturada (EFE) de Féres-Carneiro (2005).

A forma mais comum de se utilizar a técnica é solicitar à família que desenhe "sua árvore genealógica", sendo a família mais sensível à palavra árvore e a toda liberdade de imaginação que a acompanha. Em uma folha grande, guardadas as instruções e explicações sobre os sinais convencionais utilizados na construção de um genograma, deve-se anotar o nome de cada pessoa, descrever e explicar suas relações com os demais. O material é rápido, revelador e rico em conteúdo, o que permite progresso e desenvolvimento na tomada de consciência. Devido à sua complexidade, pode ser trabalhado em uma ou várias sessões e por se tratar de técnica gráfica e desenho, o seu efeito de extraterritoriedade "afasta parcialmente o recalque permitindo a passagem do conteúdo fantasmático e amortecendo a emoção", tornando a produção uma transcrição fiel do inconsciente (EIGUER, 1995, p. 209-210).

Desta maneira, o "grafismo" pode ser analisado como um desenho projetivo em que deve ser observado o investimento dos espaços em branco, volumes e deformações dos ramos familiais, posição geral na folha, como a árvore é construída e sua progressão, traços e o tipo de representação bem como o layout escolhido para a árvore e a temporalidade - investigando por quem começa ou termina a árvore, a ordem de sucessão entre gerações e a posição básica das crianças no nascimento de uma árvore. A este respeito, Cuynet e Mariage (2004) realizaram um estudo sistemático com o desenho da árvore genealógica familiar, o qual sempre foi bastante utilizado como objeto mediador na terapia familiar psicanalítica, considerado este um instrumento com verdadeiro potencial para se tornar um teste projetivo específico para o grupo familiar. Capaz de representar a estrutura inconsciente da imagem do corpo familiar, "a árvore genealógica é uma oportunidade para expressar memórias e até certos segredos graças à área de transição que existe entre o espaço intrapsíquico e o intersubjetivo" (CUYNET; MARIAGE, 2004, p. 176) tornandose uma oportunidade de conscientização e desenvolvimento de mitos familiares.

A construção coletiva, mediada por um objeto cultural externo, dá uma representação do self familiar e funciona como um espaço-temporal continente do corpo vivido do grupo. Assim, na visão da geografia familiar projetiva, apresentada por Cuynet e Mariage (2004, p. 180),

[...] o desenho da árvore genealógica mostra os pontos fortes e as falhas da economia do impulso dos elos entre os membros constituintes. Traz uma garantia narcísica, apoiando o ego ideal do indivíduo em sua fantasia de imortalidade e seu projeto de alteridade como um sujeito, especialmente assegurando-lhe seu lugar em pertencer ao grupo do qual ele vem.

Fica claro que, diferente das várias formas do genograma apresentado por Bowen e de como é pensado e utilizado dentro da teoria sistêmica, o desenho livre da árvore genealógica também se trata de um "dispositivo que faz parte do campo genealógico e, consequentemente, da transmissão psíquica consciente e inconsciente entre gerações" (KATZ-GILBERT, 2017, p. 137). Para os autores e pesquisadores mencionados, a realização livre da árvore genealógica permite explorar a maneira pela qual o sujeito representa suas origens e "dá acesso à representação fantasmática dos laços familiares, que se referem à filiação ascendente ou descendente, aos laços de aliança, aos vínculos fraternos ou avunculares" (KATZ-GILBERT et al., 
2017, p. 239), ou seja, ao parentesco fantasmático denominado por Eiguer e ao pacto denegativo referido por Kaës.

Nesse sentido, Franco e Sei (2015) dão foco à aplicação do genograma, na psicoterapia psicanalítica familiar como um instrumento projetivo e expressivo mais livre, evidenciando o fenômeno da transmissão psíquica. Assim, tal ferramenta funciona como objeto mediador e mobilizador dos processos psíquicos, o que possibilita um processo elaborativo do indivíduo. (ZANETTI, 2013).

Da mesma forma, o uso de objetos mediadores ao longo do processo psicoterapêutico viabiliza o acesso a conteúdos reprimidos o que permite a elaboração de materiais outrora impensáveis. Com isso, aquilo que era apenas angustiante pode ser elucidado pelo objeto mediador que está pronto para ser lido e receber um significado ao se perceber que este está inscrito na história do sujeito em determinado momento ou situação. Tomando-se o contexto continente da psicoterapia, tal movimento demonstra uma lembrança recuperada, o que lhe possibilita entrar para a cadeia associativa, ser restaurado e promover novas associações e descobertas sobre si, sobre a vida e sobre um novo mundo (ZANETTI, 2013).

Destarte, o papel da comunicação e do pensar imaginativo e criativo advindo das produções realizadas dentro de um enquadramento, principalmente quando este é mais flexível, colabora com novas possibilidades e perspectivas de resolução de conflitos. Para Franco, Almeida e Sei (2017), frente à solicitação de uma atividade como o genograma familiar, além do conteúdo produzido em conjunto, é possível observar o modo de relacionamento, os papéis ocupados e os vínculos estabelecidos por cada membro dentro do grupo familiar, o que promove o contato com a própria dinâmica de funcionamento familiar.

De acordo com o referencial psicanalítico, o genograma é considerado uma projeção da imagem inconsciente e representativa da história familiar, denominada corpo psíquico genealógico: "Eles se concentram em um nível analógico sobre o interesse de uma visão global do sintoma ao mesmo tempo individual e grupal, atual e genealógico. Em uma lógica de complexidade, permite uma abordagem que contabilize dimensões psico-somato-social e contextos culturais" (BENGHOZI, 2006, p. 12). As intervenções com base no genograma (ou do genoespaçograma do autor) mobilizam a descrição do funcionamento operatório da vida familiar, a memória dos ancestrais e dos traumatismos, os vínculos de aliança e os acontecimentos não metabolizados da história familiar. Além disso, segundo Benghozi e Galery (2010, p. 189-190), “o jogo das lealdades genealógicas transmitidas pode ser esclarecido pela escolha dos sobrenomes e pela maneira como se veiculam os mitos por meio de certos rituais, alguns objetos de família, slogans e emblemas familiares". Assim, quando construído no espaço da sessão, ilustra a organização dos vínculos genealógicos e dá acesso a uma figuração da transmissão psíquica. (BENGHOZI, 2006; BENGHOZI; GALERY, 2010).

A prática do genograma associa-se a uma espécie de "rabisco winicottiano" que permite modelar uma história em dinâmica relacional. Por se diferenciar do interrogatório sobre a anamnese individual e familiar, aponta ser um instrumento bastante interessante quando utilizado durante as consultas com crianças. Todavia, ressalva-se que

[...] o objetivo do genograma não é trazer uma descrição detalhada e completa da manutenção da casa familiar ou da árvore genealógica da criança, mas é a ocasião, pela evocação das fratrias, ascendentes, descendentes, a partir da recepção do paciente sintomático que vem para consultar, restituir seu advento, seu lugar na história individual, destacando as várias formas de relação na transmissão genealógica e na vida interrelacional. ${ }^{3}$ (BENGHOZI, 2006, p. 12).

Deste modo, Kaës $(2005$, p. 29) avalia que o que garante a função simbolizante não é o objeto mediador, intermediário ou transicional, mas sim 
o fato do espaço e do objeto intermediário serem apresentados por um sujeito a um outro sujeito, de modo que "ele possa ser inventado-criado por um e por outro num acompanhamento mútuo". Quer-se com isso dizer que o que é terapêutico nos grupos de mediação são as "possibilidades das trocas intersubjetivas - conscientes, inconscientes e imaginárias - as quais permitem a transformação do objeto mediador, seja ele qual for". Logo, entendese que, a sinergia reunida na troca intersubjetiva, entre espaço e objeto mediador, é um dos elementos que favorecem o acesso ao pensamento metafórico, etapa essencial para o trabalho de processos característicos para a mobilização do préconsciente e da simbolização. (VACHERET, 2015). Sendo assim, o uso do elemento mediador em grupos terapêuticos pode restabelecer a capacidade associativa e interpretativa do pré-consciente, funções vitais para a psique. (ZANETTI, 2013).

Do ponto de vista de Kaës (2005), as perturbações que afetam a atividade do pré-consciente - lugar tópico dos processos de construções intermediárias -afetam igualmente o processo de sublimação e o trabalho de simbolização. Segundo o autor, tais perturbações estão sempre presentes e funcionam como pano de fundo dos transtornos relacionados à separação precoce e aos traumatismos cumulativos e sobredeterminados bem como dos lutos coletivos difíceis de serem elaborados, consecutivos às catástrofes naturais (tremores de terra, inundações, usinas químicas) e catástrofes intencionais (guerra, violência de estado, genocídios).

Como exemplo da utilização do objeto mediador, nestas situações citadas como pano de fundo, menciona-se a pesquisa recente de Gilbert, Bourguignon e Piccolo (2016). Os autores investigaram a filiação catastrófica com descendentes das vítimas de Shoah, por meio de um trabalho de memorização e historicização com o desenho livre da árvore genealógica. Para eles, o trabalho de recordação compartilhada permite conhecer o enredo da história genealógica, escrito em várias vozes e baseado nos registros que permitem uma ancoragem espaço-temporal da história do sujeito. Desse modo, aqueles que sofreram genocídio e sobreviveram ao inferno dos campos de guerra, tortura ou exílio, muitas vezes enfrentam o cotidiano "impregnado por fantasmas dos traços traumáticos do passado" (GILBERT; BOURGUIGNON; PICCOLO, 2016, p. 71). Assim, aquilo que foi deixado para trás pelos pais "ligase à família por alianças inconscientes, por vezes estruturantes, gerando uma dinâmica de transmissão psíquica entre gerações, geralmente, a serviço do negativo, onde o elo intersubjetivo é entrelaçado no tecido do silêncio mortal, como é o caso de certos pactos de negação" (GILBERT; BOURGUIGNON; PICCOLO, 2016, p. 71).

Em tal contexto, o convite para fazer livremente sua árvore genealógica evoca a rememorização e, com o auxílio do gesto gráfico e da palavra do sujeito, o processo do recordar favorece o registro e a reintegração da memória sofrida. A mediação pelo enredo e a função continente dos afetos atribuídos pelo encontro singular com o terapeuta ou, neste caso, pelo pesquisador clínico, abre espaço para o depósito/registro e a transformação da história contada por sua autoria. (GILBERT; BOURGUIGNON; PICCOLO, 2016). A função da transformação passa, então, por meio de um conjunto de projeções, introjeções e identificações projetivas, em sua forma de processo de comunicação é revelado pela cadeia associativa grupal. (PICCOLO, 2017).

\footnotetext{
3 Tradução Livre: “L'objectif n'est pas la description détaillée et complete en un entretien de la maison ou de l'arbre généalogique de la famille de l'enfant, mais c'est l'occasion, par l'évocation des fratries, des ascendants, des descendants, en partant de l'accueil du patient porte-symptôme qui amène à consulter, de resituer son avènement, la place qu'il occupe dans l'histoire individuelle, tout en mettant en relief les diverses modalités du lien de la transmission généalogique et de la vie interrelationnelle."

4 Tradução livre: “[...]imprégné par les fantômes des traces traumatiques du passe.”
} 
Nesta direção, baseado na teoria kaësiana, entende-se que a própria atividade e a formação do pré-consciente dependem, em parte, do pré-consciente do outro, de sua capacidade de comunicação e rêverie (Bion), bem como de sua capacidade de conter e de transformar certas formações psíquicas do outro tal como a função de porta-voz (Piera Aulagnier), do outro maternal com capacidade para significar-interpretar, produzindo signos e significantes.

“As patologias do pré-consciente só podem ser tratadas e compreendidas à medida que o trabalho do pré-consciente do outro (essencialmente por sua atividade de colocar em palavras e em fala endereçada a um outro) restabelece as condições de uma retomada da atividade de simbolização". (KÄ̈S, 2005, p. 68).

Ainda sobre isso, Vacheret (2015, p. 93) complementa: "O grupo traz associações, manifesta sua cadeia associativa própria, até o momento em que um conteúdo, transitando pelo objeto mediador, faz eco e produz um ponto de ligação de sentido, altamente significativo para aquele que se reconhece nele" e afirma: "é como se o outro pensasse por mim e dissesse o que me toca, sem saber a que ponto ele fala de mim, de minha história, de meus desejos, de minhas emoções ou de meus traumatismos" (VACHERET, 2015, p. 93).

Quando se trabalha a intersubjetividade no espaço grupal, as relações mediadoras estabelecidas por objetos sensoriais ou culturais pré-construídos têm por objetivo oferecer de modo mais eficaz a possibilidade de representação ao "ativar ou reanimar certos processos psíquicos não mobilizáveis ou modificáveis de outro modo". (KAËS, 2005, p. 47). Assim, "a qualidade da mediação utilizada tem papel específico nesse tipo de trabalho do vínculo". (KÄ̈S, 2005, p. 47). É nesse jogo do intersubjetivo que alguém assume o papel de porta-voz e historiador relatando a parte estranha no que é familiar e a parte familiar no que é estranho. Deste modo, "esse duplo atestado é necessário à reconstituição simultânea de um tecido psíquico, social e interdiscursivo; comum e partilhado". (KÄ̈S, 2005, p. 92).

Em resumo, estruturadas em duas fases sendo a primeira gráfica e a segunda verbal, a produção e a criação do genograma livre ou da árvore genealógica familiar em conjunto resultarão em uma produção singular, na qual a troca verbal posterior assume importância significativa para a exploração e a clarificação dos processos psíquicos envolvidos no encontro transferencial. Portanto, será na troca verbal que os processos secundários irão se sobrepor aos processos primários mobilizados no encontro, possibilitando um testemunho tanto gráfico quanto discursivo. O que transformará os dados coletados num registro de conteúdos manifestos e latentes autorizando, desse modo, notar-se os empecilhos no trabalho de simbolização, o que traz, por vezes, impasses significativos.

\section{Objeto Mediador e Trabalho em Grupo com Crianças e Adolescentes}

Segundo Kaës (2017, p. 63-64),

[...] estudar, na criança, a representação do grupo em sua relação com a da família deve permitir apreender essa relação em sua elaboração. Ainda assim, é necessário que a experiência de grupos que não o grupo familiar venha para conferir a este um valor diferencial, que também é um valor de ancoragem.

O grupo, assim como a mãe, "exerce uma função de intérprete, isto é, de tradução, de transformação dos atos ou de sinais mensageiros de um sofrimento que não pode ser dito, que necessita de uma direção e uma metabolização". (VACHERET, 2015, p. 89). Do mesmo modo que em sua função materna, René Kaës propõe que o grupo também tem função continente, propicia o enquadre e possibilita a difração da transferência. Deste modo, "o dispositivo grupal, no qual o analista apresenta um objeto mediador, favorece a entrada em jogo e o acesso ao pensamento metafórico" (VACHERET, 2015, p. 
97). O trabalho em grupo que busca desenvolver o pensamento metafórico e se utiliza de mediadores parece fazer parte das condições prévias de um "trabalho psíquico de elaboração e finalmente de simbolização" (VACHERET, 2015, p. 105).

A escolha do desenho, o qual é natural e familiar para expressão e representação da criança, como instrumento realça propriedades projetivas. Assim, a cadeia associativa grupal, a reconstrução de fatos ou cenas com ressonância traumática são feitas com base em vivências, pensamentos e estados afetivos compartilhados, antes que possam ser nomeados. Nesse sentido, o grupo de mediação garante condições mais favoráveis ao desenvolvimento deste tipo de trabalho graças às trocas intersubjetivas. (VACHERET, 2016).

Isso posto, ao avaliar a capacidade simbolizante proporcionada pelo espaço terapêutico grupal na construção conjunta do genograma - facilitador na observação dos relacionamentos, dos papéis ocupados e dos vínculos estabelecidos num grupo familiar buscou-se investigar, por meio de uma revisão de literatura, a utilização de tal ferramenta como objeto mediador e recurso expressivo em grupos de crianças e/ou adolescentes; ressaltando-se também o interesse sobre seu uso em grupo de irmãos.

\section{Método e Resultados}

O levantamento bibliográfico empreendido baseou-se numa revisão narrativa, com o intuito de se mapear o que foi produzido sobre o tema acima escolhido sem levar em conta o período temporal. Para tanto, foram realizadas pesquisas com os termos: Genogram/Genograma, Group/Grupo, Children/Crianças, nas seguintes bases de dados: SCOPUS, Web of Science, PsychInfo e Portal da Capes. À vista disso, foram selecionados 20 artigos referentes a estudos em áreas interdisciplinares ou grupos terapêuticos de tempo limitado, associados às patologias do transtorno de estresse póstraumático ou somatoformes, com crianças em idade escolar, o que se conjugou com o uso do genograma como ferramenta clínica para entrevista, avaliação e intervenção em grupos de aconselhamento multifamiliar e de orientação profissional.

A totalidade dos artigos selecionados permitiu embasar a revisão teórica; entretanto, tomandose o objetivo de investigar a aplicabilidade prática do instrumento com crianças e adolescentes, preferencialmente em grupo, incluindo o de irmãos, priorizaram-se os artigos envolvendo a área de família. Assim, foram inseridos nos resultados as pesquisas que utilizaram o genograma como apoio ou recurso facilitador para abordagem inicial com estes sujeitos, num total de 09 artigos.

\section{Análise}

Dos resultados obtidos, constatou-seque a proficuidade desta ferramenta serve para mediar intervenções e estudos nos mais diversos contextos. Observou-se, também, que o uso do genograma como recurso expressivo apareceu relacionado a crianças obesas, com problemas de saúde (Renal, HIV), com estresse pós-traumático e como técnica de apoio para coleta de história de vida com adolescentes. Para isto, tal dispositivo foi utilizado também em pesquisas de arranjos familiares em camadas populares, sobre o impacto de violência em crianças e adolescentes, em intervenção de justiça, no estudo de padrões intergeracionais de violência familiar associada ao uso de bebidas alcoólicas e principalmente como instrumento de coleta de dados em investigações. Além de ser um instrumento para avaliação de crianças, foi mencionado também como um instrumento de sucesso em aconselhamento profissional, demonstrando seus benefícios quando integrado aos programas abrangentes de orientação profissional em escolas.

Porém, vale enfatizar que não foram encontrados relatos de uso do genograma, em grupos de crianças e adolescentes dentro do campo teórico da Psicanálise, já que parece que o uso desta ferramenta como técnica de grupo para crianças e adolescentes é mais frequente em áreas interdisciplinares, nas 
teorias sistêmicas, nas de narrativa e no Serviço Social. Por outro lado, ficou claro o quão amplo e diversificado são suas possibilidades de uso, uma vez que o genograma pode ser utilizado como eficiente instrumento técnico, mediador e de pesquisa nos mais diversos contextos e situações, independentemente da abordagem teórica envolvida.

Dentre as possibilidades terapêuticas com crianças, Davis, Geikie e Schamess (1988) já tinham abordado o uso do genograma com grupo de crianças em idade de latência, provenientes de famílias reconstituídas e com uma variedade de problemas reativos, somatoformes e caracterológicos, num grupo semi-estruturado e limitado no tempo de tratamento. Os autores relataram que, com ajuda dos terapeutas, cada criança construiu seu próprio genograma, o qual foi discutido pelo grupo como um todo. Desta forma, a técnica permitiu mapear a estrutura familiar em um modelo tradicional de terapia de grupo com crianças e focalizou a comunicação manifesta do grupo bem como a simbólica, proporcionada pelo processo grupal sobre a mudança de papéis e relacionamentos familiares. Foi percebido resultado positivo pois, à medida que conseguiam estudar a estrutura de suas famílias extensas num ambiente que encorajava e proporcionava a interação normativa entre pares e o desenvolvimento emocional, os sentimentos de vergonha, culpa, raiva e perda das crianças demonstraram acentuada melhora.

Assim, este primeiro projeto de Schamess, juntamente com Davis e Geikieteve, teve como intenção reduzir a confusão sobre composição e estrutura familiar, e, ao mesmo tempo, promover o desenvolvimento emocional progressivo em crianças com idade latente, vindas de famílias desengajadas, rompidas e reconstituídas, que sofriam de transtornos somatoformes e com uma ampla gama de sérios problemas comportamentais, interpessoais e acadêmicos. Em 1990, num segundo estudo, Schamess mantém o perfil de sujeitos e discute a inter-relação entre a teoria psicodinâmicadesenvolvimental e a teoria dos sistemas familiares aplicadas ao tratamento em grupo com crianças, no qual buscou tratar e/ou supervisionar tratamentos de crianças que estavam seriamente em risco vivendo em condições de sistemas familiares extremamente disfuncionais. Nele, o pesquisador se interessa em combinar procedimentos familiares e de grupo e constrói projetos com grupos de crianças que influenciam diretamente nos papéis e relacionamentos familiares direcionados àqueles pais não colaborativos e com dificuldades em iniciar e manter o tratamento com crianças nas propostas tradicionais oferecidas pelo Serviço Social.

Nesta perspectiva, o autor partiu do pressuposto de que as crianças só podiam ser tratadas em conjunto com seus cuidadores e enfatizou que a criação de relações simbólicas, por meio da relação terapêutica, facilitava as reconstituições de papéis familiares problemáticos. Assim, o grupo era organizado de modo que a terapêutica de trabalho mais importante enfatizasse a construção e a apresentação dos genogramas familiares, com o objetivo de proporcionar às crianças um melhor entendimento sobre suas famílias e sobre o que era possível mudar.

O uso de genogramas como meio primário de comunicação incentiva as crianças a rever, reexperimentar e redefinir seus relacionamentos com os pais e outros membros de suas famílias primária e estendida. [...] $\mathrm{O}$ processo de apresentação e discussão dos genogramas individuais permite que eles revivam o rompimento de suas unidades familiares e sofram por familiares distantes ou ausentes, bem como pela perda de suas fantasias idealizadas sobre como a vida familiar "deveria ser". Ao falar abertamente sobre a mudança de estruturas familiares, os membros começam a aceitar que outras crianças também sofreram perdas significativas, e que não é necessário que se sintam estigmatizados por suas próprias perdas e que, como indivíduos, eles não são responsáveis pelo rompimento de suas unidades familiares. O método é particularmente útil porque incentiva construir novos sistemas de significados que as ajudam a entender suas relações com membros significativos da família. (SCHAMESS, 1990, p. 89). 
Schwab (1997) escreveu sobre possíveis razões de comportamentos exibidos por crianças frente à morte de um irmão e da não elaboração do luto parental, sugerindo o genograma em um grupo de apoio às crianças como um meio para pais e crianças identificarem a perda, o que ajudava a família a falar sobre a morte. Segundo o autor, o sofrimento das crianças dependia de suas idades e do estágio de desenvolvimento, já que, muitas vezes sem conseguir comunicar-se verbalmente, o luto era mostrado de formas variadas, inclusive pelo segredo, como um desejo desesperado em proteger os pais e manter a família unida. Ficava evidente a necessidade de auxiliar diretamente as crianças para lidarem com sua experiência de perda, além de ajudar os pais a entenderem as diversas maneiras pelas quais elas eram afetadas pela morte de um irmão. Além disso, "substituir" um irmão falecido fazia com que a criança perdesse sua própria identidade e, nesse sentido, era prudente que os profissionais considerassem a perda na família como uma possível fonte de problemas onde haveria a necessidade de se trabalhar a culpa, a permissão para reconhecer sua profunda perda e o desespero que estaria por trás da dor compartilhada.

Segundo o autor, o uso de um genograma no início do grupo terapêutico era uma maneira de identificar, de forma discreta, experiências passadas de perda que poderiam estar relacionadas aos problemas atuais. Assim também, qualquer intervenção deveria concentrar-se na facilitação da comunicação aberta entre os membros e objetivar ajudá-los no que dissesse respeito à dor escondida ou não resolvida. Quando a dor sobre a morte de uma criança era reconhecida e permitida ser compartilhada abertamente na família, isto facilitava o trabalho de luto bloqueado anteriormente, aliviando as tensões no grupo e transformava "o fantasma da criança perdida" em uma memória, liberando-os (pais e irmãos vivos) para relacionamentos amorosos, desenvolvimento e vida criativa. (SCHWAB, 1997).

Assim como Schwab (1997), Cardim e Moreira (2013) utilizam o genograma no início das intervenções. Porém, neste caso, como um facilitador para o contato inicial com adolescentes que vivem com HIV/AIDS por transmissão vertical. Em tal perspectiva, a pesquisa teve como objetivo a construção da história de vida pela narrativa colhida em uma conversa, mediada e antecedida pelo desenho da rede familiar de referência, via o recurso e a dimensão lúdica do genograma com enfoque na experiência do adoecimento, no manejo e no impacto da enfermidade em busca de cuidados para as necessidades de saúde dos 14 adolescentes participantes. O genograma mostrouse eficiente para a apreensão de dados, atingiu os objetivos propostos e apresentou resultados rápidos e satisfatórios, além de se destacar como importante recurso facilitador para a abordagem inicial entre os adolescentes, visto que o caráter lúdico permitiu a participação intensa, descontraída, prazerosa e interativa, criando uma relação positiva entre o pesquisador e os sujeitos. Neste caso, a técnica utilizada se deu através da oferta de materiais compostos por cartolina, cola, canetas e várias gravuras recortadas com personagens femininos e masculinos. Com eles, o processo de construção era feito em conjunto com o pesquisador, que auxiliava os participantes na confecção e colagem das gravuras.

Os pesquisadores observaram que alguns dos adolescentes, com histórico de adoção, não revelaram tal informação durante a construção do genograma, o que levantou a hipótese de que a preocupação daqueles indivíduos estava mais voltada para as relações atuais estabelecidas, e não com a genealogia. Assim, os participantes só revelaram os componentes da família com quem tinham relações estreitas e que eram importantes no presente, inclusive com a necessidade de incluir o cachorro como membro de família. Da mesma forma, alguns jovens não escolhiam gravuras de personagens para determinados elementos da família, mas sim elegiam figuras para aqueles com maior afinidade de afeto. No caso específico destes sujeitos - adolescentes que vivem com HIV/AIDS - 
a identificação no genograma restringiu-se àqueles que faziam parte do seu núcleo familiar e outros membros da família que tinham o conhecimento do seu diagnóstico, dando a entender que a família era formada a partir daquele "segredo do diagnóstico". Deste modo, a construção conjunta do genograma com o pesquisador possibilitou aos adolescentes "a visualização da sua estrutura familiar, trazendo reflexões sobre as suas relações com aquelas pessoas e reflexões sobre suas experiências de vida". (CARDIM; MOREIRA, 2013, p. 140). Todavia, o fato de ter o adolescente como único informante impossibilitou a construção fidedigna da estrutura familiar, tendo em vista que, muitas vezes, eles "não sabem informar idades, número de filhos ou, mesmo, nomes de tios com quem pouco têm contato" (CARDIM; MOREIRA, 2013, p. 140), e tal fator pode ser considerado um limite para estudos em que tais informações sejam estritamente necessárias.

Já Ellis e Boyan (2010), considerando o cenário dos tribunais de Justiça - a lentidão e o grande número de fracassos com que os casos de alienação parental caminham - utilizaram o genograma para avaliar sintomas de alienação parental e como uma maneira de conceituar o problema entre famílias caracterizadas por estes casos, considerados de difícil resolução por meio de métodos convencionais de terapia familiar. Aqui o uso dos genogramas ilustra as dificuldades em se estabelecer visitas normais e renegociação de famílias binucleares em casos de divórcio e conflito relacionado. Em seguida, utilizaram tal ferramenta para propor intervenções adequadas. Nesses casos, por se tratar de famílias com alto conflito, o uso do genograma serviu como "mediador" no intuito de auxiliar a resolução de litígios e mais informações sobre a parentalidade e a fronteira intergeracional entre os pais e a criança.

Um estudo bastante interessante é o de Staples et al. (2011). Eles escolheram o genograma como uma das técnicas para um programa de grupo de habilidades mente-corpo com crianças e adolescentes em Gaza, na Palestina. De acordo com uma sondagem prévia, realizada com estudantes da high school em Kosovar, que demonstrou reduzir significativamente os sintomas do Transtorno de Estresse Pós-Traumático (TEPT), os autores queriam determinar se a técnica utilizada seria igualmente eficaz na redução dos sintomas em uma unidade mais ampla de crianças em um outro contexto cultural e numa situação de conflito em curso e de alto nível de ameaça de estresse. Assim, o objetivo do grupo era precisar os efeitos de tal instrumento sobre os sintomas de transtorno de estresse pós-traumático, depressão e desesperança em crianças e adolescentes nas situações acima citadas.

Os grupos de habilidades mente-corpo aconteciam em 10 sessões, duas vezes ao dia e no prazo de uma semana, os quais incluíam meditação, imagens guiadas, técnicas de respiração, treinamento autógeno, biofeedback, genogramas e auto expressão por meio de palavras, desenhos e movimentos. O genograma em seria utilizado na $8^{\mathrm{a}}$ sessão (seguida do diálogo com o sintoma e desenho precedido pela sessão de imagem guiada). Nesta sessão, seu uso tinha como objetivo explorar o lugar da pessoa na família, tomar consciência dos pontos fortes e fracos da família e encontrar fontes de apoio entre seus membros. Os resultados mostraram que o uso de imagens guiadas, juntamente com desenhos e exercícios escritos, ajudou as crianças a descobrirem soluções intuitivas para problemas crônicos relacionados ao trauma. Além disso, os exercícios expressivos favoreceram o uso da imaginação para resolver problemas e, juntamente com as demais técnicas, incutir um sentimento de esperança nos sujeitos. Apesar das limitações de não poder trabalhar com grupo controle, o estudo piloto sugere que este programa de grupo é uma abordagem promissora para ser administrado em períodos de violência política, com o intuito de ajudar populações inteiras de crianças que foram ou continuam sendo afetadas pela guerra e outros desastres. 
Em outra abordagem, Huss e Cwikel (2008) demonstraram o uso de um genograma visualmente criativo, ou seja, menos elaborado, mais livre, no contexto de grupo para explorar a experiência fenomenológica da constelação familiar. Com uma população de estudantes de Serviço Social, discutiram a abordagem interdisciplinar entre Serviço Social, Arteterapia e Terapia Familiar. Os autores afirmaram que, em conjunto, os atributos objetivos e subjetivos dos genogramas criam uma narrativa grupal do impacto de identidade culturalmente incorporada em experiências familiares compartilhadas, visto que conecta experiências objetivas e subjetivas. Dessa forma, constataram que o genograma criativo integra com sucesso essa abordagem interdisciplinar, pois ilustra a complexa interação entre o micromundo do sujeito e as tendências macro culturais e sociais que afetam a todos nós.

Por fim, mencionamos o trabalho de Taylor, Clement e Ledet (2013) voltado para o uso do genograma com crianças e adolescentes numa abordagem pós-moderna. Segundo os autores, aprender a mecânica da construção de genogramas pode ser um desafio para adultos, e, principalmente, para crianças e adolescentes. Assim, propõem formas criativas e ampliadas na construção de tais ferramentas, que englobam construções interacionais para ajudar essa população a descrever suas relações com familiares e outras pessoas importantes. No artigo, os autores expõem sete técnicas criativas e seu uso através de uma abordagem pós-construtivista, nas quais o genograma se tornou o veículo por meio do qual a sessão foi realizada, problemas foram explorados, os apoios foram descobertos e novas tentativas de resolver problemas antigos foram criados. Posteriormente, elas permitiram avaliar as mudanças nos relacionamentos e nas dinâmicas familiares. Dentre as técnicas apresentadas, vale ressaltar a associação dos genogramas com alguns recursos pertencentes às tecnologias da comunicação, como as redes sociais e os celulares.

\section{Considerações Finais}

A prática do genograma familiar demonstra ser uma fonte significativa de investigação sobre as dinâmicas familiares, para além do manifesto. Assim sendo, quando construído no espaço de uma sessão terapêutica, ele pode ajudar a descrever as relações familiares, as estruturas vinculares, as funções e os papéis ocupados por cada membro dentro de uma família ou um grupo. Além disso, a possibilidade de investigação com o uso do genograma ultrapassa questões da família nuclear e facilita o acesso à figuração da transmissão psíquica inter e transgeracional.

Ao explorar as relações e dinâmicas da família dentro do espaço continente da psicoterapia grupal, a mediação por meio do genograma elucida conteúdos até então impensáveis e possibilita novas descobertas e associações, transformando aquilo que era apenas angustiante em algo com um novo sentido, capaz de ser representado e verbalizado no jogo intersubjetivo.

Destarte, o genograma apresenta-se como um instrumento flexível, criativo, que se adapta a vários referenciais teóricos e oferece liberdade de adaptação de acordo com o contexto a ser utilizado, seja na clínica ou em outra área de atuação, associado a propostas de caráter curativo e preventivo. Nos resultados encontrados, observouse seu emprego em ambientes diversos, tais como escolas, clínicas-escola, tribunal de justiça, grupos de apoio, situações de catástrofes e, também, como instrumento de coleta de dados em pesquisas. Desta forma, fica evidenciada sua importância em auxiliar na descrição da dinâmica familiar e vincular, identificar pontos fortes e fracos dentro de uma família, apontar possíveis fontes de apoio entre seus membros, servir como recurso facilitador inicial e mediador no manejo e na promoção de exequíveis soluções para os conflitos que emergiram e distinguir intervenções adequadas.

Ademais, os trabalhos realizados utilizandose do genograma como recurso em grupos com 
crianças na fase de latência, com adolescentes ou em conjunto pais-filhos relataram maior compreensão do grupo familiar, desenvolvimento emocional e acentuada melhora nos sentimentos de raiva, culpa e vergonha.

Vale destacar que, segundo a revisão empreendida, não foi encontrada nenhuma referência ao uso prático do genograma como objeto mediador e recurso expressivo em grupos com crianças e/ ou adolescentes, sob o referencial psicanalítico; bem como sua utilização em grupo de irmãos. O estudo que mais se aproximou dessa temática foi o de Schwab (1997), com grupos de apoio a crianças para reconhecimento da perda e elaboração do luto perante a morte de um irmão dentro da família. $O$ autor abordou o uso do genograma, no início do processo psicoterapêutico, como um facilitador na identificação de experiências passadas de perda que estariam relacionadas a problemas atuais manifestos, no intuito de ajudar pais e crianças a lidarem com a situação da morte de um irmão.

Contudo, sem menosprezar seu caráter facilitador para acessar conteúdos latentes dessa modalidade relacional, principalmente em se tratando da clínica familiar, enfatiza-se como conclusão que a flexibilidade no uso do genograma incita a pensar nas várias possibilidades de seu emprego, inclusive no uso específico com grupos de irmãos e na investigação dos vínculos horizontais, que até o momento não foram tão aprofundados na psicanálise quando comparados com a vasta bibliografia existente sobre as relações parentofiliais.

\section{Referências}

BENGHOZI, P.; GALERY, E. D. Malhagem, filiação $e$ afiliação: psicanálise dos vínculos: casal, família, grupo, instituição e campo social. São Paulo: Vetor, 2010.

BENGHOZI, P. J. Le spaciogramme en thérapie psychanalytique de couple et de famille. Dialogue, Paris, n. 2, p. 5-24, 2006. Disponível em: <https://www.cairn. info/revue-dialogue-2006-2-page-5.htm>. Acesso em: 28 mar. 2018.
CARDIM, M. G.; MOREIRA, M. C. N. Adolescentes como sujeitos de pesquisa: a utilização do genograma como apoio para a história de vida. InterfaceComunicação, Saúde, Educação, Botucatu, v. 17, n. 44, p. 133-143, 2013. Disponível em: <http://www.scielo.br/ scielo.php?script=sci_arttext\&pid=S141432832013000 100011\&lng=en\&nrm=iso $>$. Acesso em: 28 mar. 2018.

CERVENY, C. M. O. Genograma e suas associações com outras técnicas. In: O livro do genograma. São Paulo: Roca, 2014. p. 13-23.

CORREA, O. B. R. Os avatares da transmissão psíquica geracional. São Paulo: Escuta, 2000.

COSTA, R. Representação gráfica de famílias com recurso ao Genopro $\AA$ : (re) descobrir o genograma familiar no contexto da investigação qualitativa. Indagatio Didactica, Aveiro, PT, v. 5, n. 2, p. 723-733, 2013. Disponível em: <http://revistas.ua.pt/index.php/ ID/article/view/2486/2354>. Acesso em: 28 mar. 2018.

CUYNET, P.; MARIAGE, A. Le dessin de l'arbre généalogique comme épreuve projective. Le Divan Familial, Paris, n. 2, p. 161-182, 2004. Disponível em: $<$ https://www.cairn.info/revue-le-divan-familial-2004-2page-161.htm>. Acesso em: 28 mar. 2018.

DAVIS, L.; GEIKIE, G.; SCHAMESS, G. The use of genograms in a group for latency age children. International Journal of Group Psychotherapy, New York, v. 38, n. 2, p. 189-210, 1988.

EIGUER, A. O parentesco fantasmático: transferência e contratransferência em terapia familial psicanalítica. São Paulo: Casa do Psicólogo, 1995.

ELLIS, E. M.; BOYAN, S. Intervention strategies for parent coordinators in parental alienation cases. The American Journal of Family Therapy, New York, v. 38, n. 3, p. 218-236, 2010.

FÉRES-CARNEIRO, T. Entrevista familiar estruturada: um método clínico de avaliação das relações familiares. São Paulo: Casa do Psicólogo, 2005.

FRANCO, R. S.; ALMEIDA, M. C. S.; SEI, M. B. Recursos artístico-expressivos na terapia familiar: um estudo teórico-clínico. Revista de Psicologia da UNESP, Assis, v. 15, n. 1, p. 40-52, ago. 2017. Disponível em: $<$ http://seer.assis.unesp.br/index.php/psicologia/article/ view/276>. Acesso em: 28 mar. 2018.

FRANCO, R. S.; SEI, M. B. O uso do genograma na psicoterapia psicanalítica familiar. Gerais, Revista Interinstitucional de Psicologia, Juiz de Fora, v. 8, n. 2, p. 399-414, dez. 2015. Disponível em: <http://pepsic. bvsalud.org/scielo.php?script=sci_arttext\&pid=S1983$82202015000300009 \& \operatorname{lng}=\mathrm{pt \& nrm}=\mathrm{iso}>$. Acesso em: 28mar. 2018. 
GILBERT, M. K.; BOURGUIGNON, M.; PICCOLO, G. Filiation catastrophiqueet travail de mémoire après la Shoah: quand la libreréalisation de l'arbregénéalogiqueest au service de l'historicisation. Dialogue, Paris, n. 3, p. 69-82, 2016. Disponível em: <https://www.cairn.info/ revue-dialogue-2016-3-page-69.htm>. Acesso em: 28mar. 2018.

HUSS, E.; CWIKEL, J. "It's hard to be the child of a fish and a butterfly": creative genograms: bridging objective and subjective experiences. The Arts in Psychotherapy, London, v. 35, n. 2, p. 171-180, 2008. Disponível em: $<$ https://www.researchgate.net/publication/223051848>. Acesso em: 30 maio 2018.

KAËS, R. As alianças inconscientes. São Paulo: Ideias e Letras, 2014.

KAËS, R. Espaços psíquicos comuns e partilhados. São Paulo: Casa do Psicólogo, 2005.

KAËS, R. Les théories psychanalytiques du groupe. Paris: Presses Universitaires de France, 2017. (Que Saisje? n. 3458). Disponível em: <https://www.cairn.info/ theories-psychanalytiques-du-groupe--0782130792390. htm>. Acesso em: 28 de mar. 2018.

KATZ-GILBERT, M. et al. Le génocide pensé comme passage à l'acte de nature fanatique: quelles répercussions psycho-sociales? Une étude de cas menée à partir de la libre réalisation de l'arbre généalogique auprès d'un survivant de la Shoah. Cahiers de Psychologie Clinique, Paris, n. 2, p. 227-258, 2017. Disponível em: <https:// www.cairn.info/revue-cahiers-de-psychologie-clinique2017-2-page-227.htm>. Acesso em: 30 maio 2018.

KATZ-GILBERT, M. Destins de la temporalité psychique et survivance après um génocide: une étude de cas à partir de la libre réalisation de l'arbre généalogique. Psychologie Clinique et Projective, Boulogne-Billancourt, n. 1, p. 135-157, 2017. Disponível em: <https://www.cairn. info/revue-psychologie-clinique-et-projective-2017-1page-135.htm>. Acesso em: 30 maio 2018.

KWIATKOWSKA, H. Y. Instruções para conduzir sessões de arte-diagnóstico familiar. Rio de Janeiro: Pontifícia Universidade Católica, 1975. Apostila do Curso de Intervenção Familiar.

MACEDO, R. M. S. Genograma: origens e usos. In: CERVENY, C. M. O. O livro do genograma. São Paulo: Roca, 2014.

MCGOLDRICK, M.; GERSON, R. Genograms en al evaluacion familiar. 3. ed. Barcelona: Gedisa, 2000.

PICCOLO, G. Processus et non-processus dans un groupe Photolangage ${ }^{\circledR}$. Dialogue, Paris, n. 4, p. 57-70, 2017. Disponível em: $<$ https://www.cairn.info/revue-dialogue2017-4-page-57.htm>. Acesso em: 30 maio 2018.
SCHAMESS, G. New directions in children's group therapy: integrating family and group perspectives in the treatment of at risk children and families. Social Work With Groups, New York, v. 13, n. 1, p. 67-92, 1990.

SCHWAB, R. Parental mourning and children's behavior. Journal of Counseling \& Development, Alexandria, v. 75, n. 4, p. 258-265, 1997. Disponível em: <https://onlinelibrary.wiley.com/doi/ abs/10.1002/j.1556-6676.1997.tb02340.x>. Acesso em: 30 maio 2018.

STAPLES, J.K. Mind-body skills groups for posttraumatic stress disorder and depression symptoms in Palestinian children and adolescents in Gaza. International Journal of Stress Management, Washington, v. 18, n. 3, p. 246, 2011.

TAYLOR, E. R.; CLEMENT, M.; LEDET, G. Postmodern and alternative approaches in genogram use with children and adolescents. Journal of Creativity in Mental Health, Binghamton, v. 8, n. 3, p. 278-292, 2013. Disponível em: <http://psycnet.apa.org/record/2011-13205-001>. Acesso em: 18 mar. 2018.

VACHERET, C. O grupo, o objeto mediador e o acesso ao pensamento metafórico. In: ABUD, C. C. (Org.). A subjetividade nos grupos e Instituições: constituição, mediação e mudança. Lisboa: Chiado Books, 2015. p. 81-113.

VACHERET, C. Pratiquer les médiations en groupes thérapeutiques. Paris: Dunod, 2016.

WACHTEL, E. F. The family psyche over three generations: the genogram revisited. Journal of Marital and Family Therapy, Malden, v. 8, n. 3, p. 335343, 1982. Disponível em: <http://psycnet.apa.org/ record/1983-02391-001>. Acesso em: 22 maio 2018.

ZANETTI, S. A. S. O uso terapêutico da mediação: um entendimento psicanalítico a respeito da produção artística. Revista de Arteterapia da AATESP, São Paulo, v. 4, n. 2, p. 48-55, 2013.

ZUSE, A. S.; ROSSATO, V. M. D.; BACKES, V. M. S. Genetograma: um instrumento de trabalho na compreensão sistêmica de vida. Revista LatinoAmericana de Enfermagem, Ribeirão Preto, v. 10, n. 3, p. 308-320, 2002. Disponível em: <http://www. scielo.br/scielo.php?script $=$ sci_arttext\&pid $=\mathrm{S} 0104$ $11692002000300006 \& \operatorname{lng}=\mathrm{en} \& \mathrm{nrm}=\mathrm{iso}>$. Acesso em: 13 abr. 2018.

Recebido em: 31 maio 2018 Aceito em: 15 ago. 2018 